\title{
Analyzing Students’ Cognitive Load to Prioritize English Public Speaking Training
}

\author{
Yow-Jyy Joyce Lee \\ Department of Applied English, National Taichung University of Science and Technology, Taichung City, Taiwan \\ Email: yjlee@nutc.edu.tw
}

Received June 7, 2013; revised July 12, 2013; accepted August 6, 2013

Copyright (C) 2013 Yow-Jyy Joyce Lee. This is an open access article distributed under the Creative Commons Attribution License, which permits unrestricted use, distribution, and reproduction in any medium, provided the original work is properly cited.

\begin{abstract}
This paper applies the Hierarchy Grey Relational Analysis (HGRA) for data analysis obtained from the EFL students' cognitive load in English public speaking. Thirty-one EFL students in a class of English Presentation Training participated in the experiment and the teacher familiarized them with nine criteria of abilities in public speaking training. The participants were then asked to reflect on their own confidences in the same criteria. A framework employing HGRA was developed to analyze the data. The results show that from the easiest to the most difficult, the cognitive confidence in sequence of the participants is $S(21) \rightarrow S(27) \rightarrow S(25) \rightarrow S(16) \rightarrow S(12), \ldots, \rightarrow S(2)$, and in sequence of criteria is $C(1)$ Posture $\rightarrow C(5)$ Preparing effective visual aids $\rightarrow C(2)$ Eye contact $\rightarrow C(3)$ Gestures $\rightarrow C(6)$ Explaining visual aids $\rightarrow C(4)$ Voice variation $\rightarrow C(9)$ Closing the speech $\rightarrow C(7)$ Opening the speech $\rightarrow C(8)$ Organizing \& outlining the speech body. Based on the findings, in order to tailor to students' cognitive load for best training results, the teacher should start from easier, more concrete techniques such as motor skills and preparing effective visual aids, and finally proceed to the abstract, logical organization of the main points. Additionally, the teacher can even offer differentiated practices to those whose cognitive load level in speech skills are different.
\end{abstract}

Keywords: English Public Speaking; Cognitive Load; Hierarchy Grey Relational Analysis (HGRA); Instructional Design

\section{Introduction}

In a required EFL public speaking course, most of the students are novice public speakers at the time of enrollment. Faced with a new subject to be learned, it is very important that students feel successful. Zheng [1] suggested that unpleasant learning experience could become a traumatic experience under some circumstances and might bring down a learner's self-esteem and self-confidence. MacIntyre [2] argued that anxiety derived from negative experiences early in language learning experience. In short, feelings of success and low anxiety facilitate learning [3]. Cognitive load theory assumes human cognitive resources to be limited. When a learning activity requires more cognitive capacity than what a learner is equipped with, it causes an overload on the learner's cognition, which eventually results in failure in the learning activity [4]. What cognitive load theory seeks, therefore, is the teaching materials and activities appropriately designed to lower learners' cognitive load, by which learning effectiveness is enhanced. These studies support the view that beginners' experience is critical to their future learning success. What speech educator should do, hence, is to alleviate students' worries and anxieties in the first place by carefully planning the curriculum and the pedagogical materials to ensure a successful learning experience bestowed on novice speaker from the outset.

The project herein aims to sort out the skills which students feel most confident in and generate least anxiety. If the speech instructor approaches teaching students in this direction, then students' cognitive load is more likely to be in line with their learning. In turn, students feel more prepared to be challenged by further "difficult" techniques in public speaking.

Hence, this study proposes a data analysis procedure utilizing the Hierarchy Grey Relational Analysis (HGRA) method, which combines the Analytic Hierarchy Process (AHP) to derive the weight of nine speech attributes and then inputs the weights to the Grey Relational Analysis (GRA) method. It is anticipated that this study can delineate the confidence patterns from the data of EFL students' perspectives so that teachers can develop more effectual instructional design. 
The rest of this paper is organized as follows. The rationales for the proposed data analysis procedure are briefly reviewed in the next section. The subsequent sections address the procedures of data analysis, the experimental results, and the pragmatic implications.

\section{Literature Review}

\subsection{The Hierarchy Grey Relational Analysis (HGRA) Method}

To investigate the EFL students' cognitive learning confidence in English public speaking, this study introduces an integrated model - the Hierarchy Grey Relational Analysis (HGRA), which combines the AHP and GRA into a single evaluation model. In fact, this HGRA integrated model has been used by other researchers to evaluate the correlation between data sequences in different contexts [5-7].

\subsubsection{The Analytical Hierarchy Process (AHP) Method}

AHP is frequently used to analyze the multi-attribute decision systems. Generally, the AHP assumes a unidirectional hierarchical relationship among decision levels - the top element of the hierarchical structure is the overall goal (s) for the decision model, and the hierarchy devolves to more specific attributes until a level of manageable decision criteria is met. Each element in the hierarchy is assumed independent of one another; namely, the decision criteria must be independent of all the others, and the alternatives are independent of the decision criteria and of each other. AHP employs a system of pairwise comparisons to measure the weights or to ratio the scale priorities of the elements by the matrix of linear algebra, and finally to rank the priority of the alternatives in the decision [8,9]. To avoid the dataset inconsistency when making the pairwise comparisons, the AHP procedures produce a consistency index $(\mathrm{CI})$. If $\mathrm{CI}<0.1$, it means the dataset is consistent and clean [9]. Applications of the AHP technique can be found in different fields (e.g., business, industry, government, healthcare, education, among others) for choosing the favorite alternative from a given set of alternatives and for other purposes such as ranking, prioritization, resource allocation, benchmarking, quality management, and conflict resolution [10-12].

\subsubsection{The Grey System Theory and the Grey Relational Analysis (GRA) Method}

The grey system theory was first proposed by Deng [13]. Its primary purpose is to perform relational analysis and model construction when dealing with discrete, uncertain, multi-dimensional, and incomplete data. Among the many analytical tools developed for grey system theory, GRA is one of the most effective experimental processes.
The functions of GRA are to quantify the factors, to quantitatively measure the distributed time series effects and conflicting beliefs, and to examine the effective relative index by means of systematic application [14]. It does not need a great amount of data, the results are based on original data, and the calculations are simple and easy to understand. The grey system theory has been proven an alternative to traditional multivariate statistical methods (e.g., factor analysis and regression analysis). Thus, the GRA has become one of the best methods to guide the selection process through the ordinal process and has helped a decision maker solve the selection problem, particularly when there are multiple and contradictory objectives to be considered. Now GRA has been applied in many fields such as product design [15, 16], market survey [17], education [18,19], material science [20], and information management [21].

\subsection{Cognitive Load Theory}

Adopting the perspective of information processing theory and as part of cognitive psychology, Sweller first introduced cognitive load theory to be applied in education in the 1980s. Under its assumption that human cognitive capacity is limited, learning difficulty arises when an overwhelming amount of information in need of being processed exceeds the working capacity [22]. Cognitive load theory was proposed to provide guidelines to lower learners' cognitive load and help pedagogy encourage learner activities that optimize learning output.

Cognitive load theory aims at discovering the relationships between cognitive processing and instructional design. Research found that cognitive load exerted great influence in teaching and learning [23-25]. There also has been research producing results as useful pedagogical reference [24,25].

Cognitive load theory and the results of the study provide a direction for teachers to ponder on the design of pedagogical materials, presentation of the materials, and the interpretation of learning difficulties experienced by students. Firstly, to lessen students' cognitive load, teaching materials should be prepared and introduced from easy to difficult sequence to effectively assist students with practicing the abilities, which ultimately internalized into automatic schema. Such arrangement based on cognitive load theory will establish students' confidence and skills. Secondly, the a priori knowledge, which affects the status of cognitive load in students, should be investigated at the onset of the course. Remedial treatment should be provided if it is found inadequate. Thirdly, inappropriate pedagogical materials/skills create cognitive overload. Hence, teachers should select appropriate teaching methods and presentation of the teaching materials according to the students' level and 
the nature of the teaching materials. Fourth, the construction of schemas is highly related to cognitive load and is beneficial to learning. Hence, instructors should provide systematic practices to install automatic knowledge/skills output or schema in students' capacity.

Therefore, using the theoretical framework of cognitive load, it is argued that the characteristics of the structures that constitute human cognitive architecture need to be taken into account in the design of effective and efficient instruction.

\section{Data Analysis Procedure}

Specifically, pairwise comparisons of difficulty level between any two criteria are answered by all responding students and the AHP procedure is then used to derive AHP weights and test the dataset consistency. Moreover, the AHP weights are used in the GRA procedure to evaluate the degree of correlation for different data sequences for each participant and then among the participants and criteria. The proposed procedure is further explained below.

\subsection{Identifying the Evaluation Criteria}

Central to the problem definition is the identification of evaluation criteria. This study first identifies the bestselling EFL textbook in public speaking training in Taiwan, and then extracts nine criteria of abilities from it.

\subsection{Collecting Data by Pairwise Comparison}

Each participant makes paired comparisons of elements on a common property or criterion on a ratio scale: $1 / 9$, $1 / 7.1 / 5,1 / 3,1,3,5,7$, and 9 . The ratio scale priorities of each participant forms a subset of a larger dataset collected from all participants.

\subsection{Computing AHP Weights and Testing Data Consistency}

The AHP weights of criteria for each participant are computed by AHP procedure. AHP weights are first derived from ratio scale priorities. Let $C_{j, m}$ denote the criterion $m$ for participant $j$, the weights of criteria for all participants $[W]_{j}$ can be expressed as

$$
\begin{aligned}
& \begin{array}{lllll}
C_{\mathrm{j}, 1} & C_{\mathrm{j}, 2} & C_{\mathrm{j}, 3} & \cdots & C_{j, m}
\end{array} \\
& {[W]_{j}=\begin{array}{c}
C_{j, 1} \\
C_{j, 2} \\
C_{j, 3} \\
\vdots \\
C_{j, m}
\end{array}\left[\begin{array}{ccccc}
1 & w_{12} & w_{13} & \cdots & w_{1 m} \\
w_{12}^{-1} & 1 & w_{23} & \cdots & w_{2 m} \\
w_{13}^{-1} & w_{23}^{-1} & & \cdots & \\
\vdots & \vdots & \vdots & \ddots & \vdots \\
w_{1 m}^{-1} & w_{2 m}^{-1} & w_{3 m}^{-1} & \cdots & 1
\end{array}\right]_{j}, j=1,2, \cdots, n}
\end{aligned}
$$

In addition, through the AHP procedure the data in all comparative sequences are verified by the Consistency Index $(C I)$ to be clean. When $C I \leq 0.1$, the consistence of the pairwise comparison matrix is acceptable.

The $C I$ can be computed as $C I=\frac{\lambda_{\max }-m}{m-1}$

In this study, the $C I$ verification will be repeated 31 times on each participant.

\subsection{Establishing the Raw Data of Grey Relation}

To set up the GRA matrix, the reference vector $x_{0}$ and the comparative vector $x_{j}$ are required [26].

$$
\left.\begin{array}{c}
x_{0}=\left(x_{0}(1), x_{0}(2), \cdots, x_{0}(k), \cdots, x_{0}(m)\right) \\
k=1,2,3, \cdots, m \\
x_{i}=\left(x_{1}(1), x_{1}(2), \cdots, x_{1}(k), \cdots, x_{1}(m)\right) \\
x_{i}=\left(x_{2}(1), x_{2}(2), \cdots, x_{2}(k), \cdots, x_{2}(m)\right) \\
\vdots \\
x_{n}=\left(x_{n}(1), x_{n}(2), \cdots, x_{n}(k), \cdots, x_{n}(m)\right) \\
i=1,2,3, \cdots, n
\end{array}\right\}
$$

If $x_{0}$ is the reference vector and the rest of vectors serve as comparative vectors, it is called localization GRA (LGRA). If any $x_{j}$ can serve as a reference vector, it is called globalization GRA (GGRA). In this study, LGRA is adopted because LGRA is usually used for ranking purposes while GGRA is used for weighting purposes.

\subsection{Normalization of the Raw Data of Grey Relation}

This step seeks to normalize the raw data, denoted below, for GRA procedures.

$$
\begin{aligned}
x_{j}^{*} & =\left(x_{j}^{*}(1), x_{j}^{*}(2), \cdots, x_{j}^{*}(k), \cdots, x_{j}^{*}(m)\right) \\
j & =1,2, \cdots, n
\end{aligned}
$$

The raw data must satisfy three conditions, i.e. nondimension, scaling and polarization, before the comparability of the series is established. There are three methods to generate and standardize the data, and they are: larger-the-better, smaller-the-better, and nominal-the-better. In this paper, large-the-better denoted below is applied,

$$
\begin{aligned}
x_{i}^{*}(k) & =\frac{x_{i}(k)-\min _{i} x_{i}(k)}{\max _{i} x_{i}(k)-\min _{i} x_{i}(k)} \\
j & =1,2, \cdots, n
\end{aligned}
$$

where $\max _{i} x_{i}(k)$ means the maximum number in $j$ and $\min _{i} x_{i}(k)$ means the minimum number in $j$. 


\subsection{Using AHP Weights as Raw Data to Calculate Individual Grey Relation Grade}

This study adopts Nagai's GRA formula [14] for this step. Let $\Gamma$ denote a localization grey relational grade (LGRG) value, and the reference vector is $X_{0}$ and the comparative vector is $\mathrm{X}_{\mathrm{i}}$,

$$
\Gamma_{0 i}=\Gamma\left(x_{o}(k), x_{i}(k)\right)=\frac{\bar{\Delta}_{\max }-\bar{\Delta}_{0 i}}{\bar{\Delta}_{\max }-\bar{\Delta}_{\min }}
$$

where $\quad \bar{\Delta}_{0 i}=\left\|x_{0 i}\right\|_{\rho}=\left(\sum_{k=1}^{n}\left[\Delta_{0 i}(k)\right]^{\rho}\right)^{\frac{1}{\rho}}$ where $\bar{\Delta}_{\max }$ represents the maximum value of $\bar{\Delta}_{0 i}$, and $\bar{\Delta}_{\text {min }}$ represents the minimum value of $\bar{\Delta}_{0 i}$.

$\Gamma_{0 i}$ is compared in the decision-making process. The larger $\Gamma_{0 i}$ value, the more important the factor is. This rule serves as the ranking principle of the system. When $\Gamma_{0 i}$ approaches 1 , it indicates that $X_{0}$ and $X_{i}$ are highly related to each other; when $\Gamma 0 \mathrm{i}$ approaches 0 , it indicates that $X_{0}$ and $X_{i}$ are not related to each other.

The step will be repeated 31 times on all participants' subset, yielding 31 sets of LGRG values for the next step.

\subsection{Grey Relational Ordinal for Participants and Criteria}

Using the individual LGRG values from the above step, Nagai's GRA formula [14] is adopted again twice for this step to compute both students' and criteria's LGRG values. In the first execution, LGRG values of the participating students are aggregated, with the students serving as the $\mathrm{Y}$ axis and the criteria serving as the $\mathrm{X}$ axis in the GRA matrix. In the second execution, the LGRG values of the criteria are aggregated, with the criteria serving as the $\mathrm{Y}$ axis and students serving as the $\mathrm{X}$ axis in the GRA matrix.

\subsection{Constructing a Consolidated Matrix}

The two sets of LGRG values, one from the participants and one from the criteria, from the above step are ranked into a consolidated matrix.

\section{Experiment}

\subsection{Research Design}

A project was designed wherein nine evaluation criteria were identified to decipher the participants' cognitive confidence in each construct. The nine criteria were adopted directly from the best-selling textbook Speaking of Speech (New/e) [27] in Taiwan according to data obtained by a survey with the top-five major EFL textbook dealers in the year of 2012. A total of nine criteria, coded as $\mathrm{C}(1)-\mathrm{C}(9)$, together with their corresponding training elements were identified in this textbook. The nine criteria of abilities in public speaking include $C(1)$ Posture, $C(2)$ Eye contact, C(3) Gestures, C(4) Voice inflection, $C(5)$ Preparing effective visual aids, C(6) Explaining visual aids, C(7) Opening the speech, C(8) Organizing and outlining the speech body, and C(9) Closing the speech (Table 1).

Table 1. The targeted abilities in Speaking of Speech.

\begin{tabular}{|c|c|c|}
\hline \multicolumn{2}{|c|}{$\begin{array}{c}\text { Constructs in the public } \\
\text { speaking training }\end{array}$} & Training elements \\
\hline $\mathrm{C}(1)$ & Posture & $\begin{array}{ll}\text { - } & \text { Maintain a good posture } \\
\text { - } & \text { Stand tall } \\
\text { - } & \text { Position the whole body }\end{array}$ \\
\hline $\mathrm{C}(2)$ & Eye contact & - Look the audience in the eye \\
\hline $\mathrm{C}(3)$ & Gestures & $\begin{array}{l}\text { - Use gestures to emphasize } \\
\text { important points \& support the } \\
\text { verbal message }\end{array}$ \\
\hline $\mathrm{C}(4)$ & Voice inflection & $\begin{array}{ll}\text { - } & \text { Tone and character of voice } \\
\text { - } & \text { Use stress to emphasize key } \\
\text { - } & \text { Breats } \\
\text { - } & \text { Adjust volume } \\
\text { - } & \text { Adjust pace/rate } \\
\text { - } & \text { Practice articulation } \\
\text { - } & \text { Pauses effectively } \\
\text { - } & \text { Stretch key words } \\
\text { - } & \text { Vary intonation/pitch } \\
\text { - } & \text { Avoid filler words }\end{array}$ \\
\hline $\mathrm{C}(5)$ & $\begin{array}{l}\text { Preparing effective } \\
\text { visual aids }\end{array}$ & $\begin{array}{l}\text { - Understand different types of } \\
\text { visuals } \\
\text { - } \quad \text { Learn different methods for } \\
\text { displaying visuals } \\
\text { - Coordinate body language } \\
\text { with visuals } \\
\text { - } \quad \text { Use proper equipments } \\
\text { - Select explaining phrases for } \\
\text { visuals' maximum output }\end{array}$ \\
\hline$C(6)$ & $\begin{array}{l}\text { Explaining visual } \\
\text { aids }\end{array}$ & $\begin{array}{l}\text { Explain visuals for their } \\
\text { maximum output }\end{array}$ \\
\hline$C(7)$ & Opening the speech & $\begin{array}{l}\text { - Use openers techniques } \\
\text { - } \text { Engage the audience from the } \\
\text { start } \\
\text { - } \quad \text { Provide a preview } \\
\text { Establish a compassion with } \\
\text { the topic }\end{array}$ \\
\hline $\mathrm{C}(8)$ & $\begin{array}{l}\text { Organizing \& } \\
\text { outlining the speech } \\
\text { body }\end{array}$ & $\begin{array}{l}\text { - } \text { Choose a topic } \\
\text { - } \text { Analyze the audience } \\
\text { - } \text { Construct a thesis statement } \\
\text { - } \text { outline } \\
\text { - Organize main points } \\
\text { - } \quad \text { Prganize subpoints } \\
\text { - } \text { Use transitions/signposts } \\
\text { - Connect the visuals into the } \\
\text { message }\end{array}$ \\
\hline $\mathrm{C}(9)$ & Closing the speech & $\begin{array}{l}\text { - Provide a summary for the } \\
\text { - } \text { Share personal experiences } \\
\text { - } \quad \text { Call for action } \\
\text { - } \quad \text { End as you started }\end{array}$ \\
\hline
\end{tabular}




\subsection{Participants}

An English Presentation Training class of 31 students, coded as S(1)-S(31), took part in this experiment. All of them were senior EFL majors from a university in central Taiwan. Throughout the semester, the participants received constant instructions on how to deliver English speech. The instructor familiarized them with the above nine criteria. At the end of the semester they were asked to reflect on their own public speech confidence in the nine criteria.

\subsection{Data Consistency and HGRA for Individual Participants}

A student skills survey measured the learning of the targeted nine abilities from the participant's perspective. Each participant was requested to make a pairwise comparison on a 9-point scale: 9, 7, 5, 3, 1, 1/3, 1/5, 1/7, 1/9 about the difficulty level between any two criteria, thus forming a sub-dataset from each participant. The AHP procedure was then employed to determine the AHP weights and the CI value of each sub-dataset. Taking student No. 1 as an example, Table 2 detailed the pairwise comparisons and nine criteria's AHP weights. The CI value was less than 0.1 , suggesting the whole dataset for this participant was consistent. All of the CI values from the 31 participants were under 0.1 , confirming the consistency of the data.

Next, with the help of the MATLAB software, GRA method was performed 31 times on each participant's set of AHP weights. Consequently, it yielded 31 subsets of LGRG values on the nine criteria.

\subsection{The LGRG Values and Rankings}

After verifying the data consistency for all participants, the LGRG values of each participant subset, obtained from the above step, were aggregated to run the GRA in MAT-
LAB in order to evaluate the 31 participants' cognitive confidence in English public speaking. In this GRA procedure, "student" served as the vertical axis and "criteria" served as the horizontal axis. Table 3 showed the results. Participant No. $21($ LGRA $=0$ ) had the most confidence in English public speaking, followed by participant No. 27 , and so on. No. $2($ LGRA = 1) had the most difficulty.

Next, in order to evaluate the nine criteria affecting public speaking confidence, GRA procedure was applied again on the LGRG values from all participant subsets. This time with "criteria" served as the vertical axis and "stu- dent" served as the horizontal axis. Table 4 showed the results. The easiest criterion perceived by the $31 \mathrm{EFL}$ participants was $C(1)$ Posture (LGRA $=0)$, followed by $C(5)$ Preparing effective visual aids, and so on. The most difficult criterion was $C(8)$ Organizing \& outlining the speech body $(\mathrm{LGRA}=1)$.

\subsection{Consolidated Ranking Table}

Finally, we consolidated the information from Tables 3 and $\mathbf{4}$ into a matrix, detailed in Table 5. In so doing, one can concurrently view both students' and criteria' sequences from the easiest to the most difficult in one matrix. The results have displayed on the vertical axis from top to bottom that from the easiest to the most difficult in sequence of the 31 participants were: $S(21) \rightarrow S(27) \rightarrow$ $S(25) \rightarrow S(16) \rightarrow S(12)$, and so on. In sequence of the nine criteria were: $C(1)$ Posture $\rightarrow C(5)$ Preparing effective visual aids $\rightarrow C(2)$ Eye contact $\rightarrow C$ (3) Gestures $\rightarrow$ $C(6)$ Explaining visual aids $\rightarrow C(4)$ Voice variation $\rightarrow$ $C(9)$ Closing the speech $\rightarrow C(7)$ Opening the speech $\rightarrow$ $C(8)$ Organizing \& outlining the speech body. The most difficult item was $C(8)$ located on the right of the horizontal axis, while the easiest item was $C(1)$ located on the left of the horizontal axis.

Table 2. The AHP pairwise comparisons and nine criteria AHP weights for participant No. 1.

\begin{tabular}{|c|c|c|c|c|c|c|c|c|c|c|}
\hline Participant 1 & $\mathrm{C}(1)$ & $\mathrm{C}(2)$ & $\mathrm{C}(3)$ & $C(4)$ & $C(5)$ & $C(6)$ & $C(7)$ & $\mathrm{C}(8)$ & $\mathrm{C}(9)$ & AHP weight \\
\hline$C(1)$ & 1 & $1 / 3$ & $1 / 3$ & $1 / 5$ & 3 & 1 & 5 & 3 & 3 & 0.0948 \\
\hline $\mathrm{C}(2)$ & 3 & 1 & $1 / 3$ & $1 / 5$ & 3 & 3 & 3 & 3 & 3 & 0.1292 \\
\hline$C(3)$ & 3 & 3 & 1 & 1 & 3 & 3 & 5 & 3 & 3 & 0.2087 \\
\hline$C(4)$ & 5 & 5 & 1 & 1 & 5 & 5 & 7 & 7 & 5 & 0.3162 \\
\hline$C(5)$ & $1 / 3$ & $1 / 3$ & $1 / 3$ & $1 / 5$ & 1 & 1 & 3 & 1 & 1 & 0.0550 \\
\hline$C(6)$ & 1 & $1 / 3$ & $1 / 3$ & $1 / 5$ & 1 & 1 & 3 & 5 & 1 & 0.0743 \\
\hline$C(7)$ & $1 / 5$ & $1 / 3$ & $1 / 5$ & $1 / 7$ & $1 / 3$ & $1 / 3$ & 1 & $1 / 3$ & 1 & 0.0290 \\
\hline $\mathrm{C}(8)$ & $1 / 3$ & $1 / 3$ & $1 / 3$ & $1 / 7$ & 1 & $1 / 5$ & 3 & 1 & 1 & 0.0443 \\
\hline $\mathrm{C}(9)$ & $1 / 3$ & $1 / 3$ & $1 / 3$ & $1 / 5$ & 1 & 1 & 1 & 1 & 1 & 0.0486 \\
\hline
\end{tabular}


Table 3. The 31 participants' LGRG values and rankings.

\begin{tabular}{|c|c|c|c|c|c|c|c|c|c|c|c|}
\hline Participants & $\mathrm{C}(1)$ & $\mathrm{C}(2)$ & $C(3)$ & $\mathrm{C}(4)$ & $C(5)$ & $C(6)$ & $C(7)$ & $\mathrm{C}(8)$ & $\mathrm{C}(9)$ & \multirow{2}{*}{$\begin{array}{l}\text { LGRG } \\
\text { (value) }\end{array}$} & \multirow{2}{*}{ Ranking } \\
\hline $\mathrm{LB}^{\mathrm{a}}$ & 0.2232 & 0.3704 & 0.3761 & 0.3789 & 0.3413 & 0.4326 & 0.4014 & 0.3839 & 0.3463 & & \\
\hline $\mathrm{S}(1)$ & 0.0948 & 0.1292 & 0.2087 & 0.3162 & 0.0550 & 0.0743 & 0.0290 & 0.0443 & 0.0486 & 0.6485 & 19 \\
\hline$S(2)$ & 0.0395 & 0.0445 & 0.0395 & 0.0395 & 0.0863 & 0.1205 & 0.2100 & 0.2100 & 0.2100 & 1 & 31 \\
\hline$S(3)$ & 0.0352 & 0.0399 & 0.0485 & 0.0813 & 0.0674 & 0.1068 & 0.0790 & 0.3696 & 0.1725 & 0.6770 & 20 \\
\hline $\mathrm{S}(4)$ & 0.0416 & 0.1094 & 0.0416 & 0.2528 & 0.0416 & 0.0416 & 0.2528 & 0.1094 & 0.1094 & 0.9260 & 29 \\
\hline $\mathrm{S}(5)$ & 0.0273 & 0.0273 & 0.0273 & 0.0273 & 0.0704 & 0.0704 & 0.4005 & 0.1961 & 0.1536 & 0.4998 & 8 \\
\hline$S(6)$ & 0.0434 & 0.0285 & 0.0259 & 0.2252 & 0.0293 & 0.0555 & 0.1177 & 0.3568 & 0.1177 & 0.5780 & 14 \\
\hline$S(7)$ & 0.0312 & 0.3531 & 0.1304 & 0.0337 & 0.0207 & 0.0388 & 0.0741 & 0.2188 & 0.0993 & 0.5666 & 13 \\
\hline $\mathrm{S}(8)$ & 0.0704 & 0.0474 & 0.1853 & 0.2751 & 0.0412 & 0.0521 & 0.1640 & 0.1015 & 0.0628 & 0.9190 & 28 \\
\hline$S(9)$ & 0.0447 & 0.1192 & 0.0635 & 0.0593 & 0.0411 & 0.0368 & 0.1222 & 0.3283 & 0.1849 & 0.7361 & 22 \\
\hline$S(10)$ & 0.0719 & 0.0315 & 0.0936 & 0.0324 & 0.0480 & 0.4326 & 0.0261 & 0.2307 & 0.0333 & 0.4410 & 7 \\
\hline $\mathrm{S}(11)$ & 0.0743 & 0.0381 & 0.0298 & 0.1356 & 0.0354 & 0.0487 & 0.2477 & 0.3162 & 0.0743 & 0.6865 & 21 \\
\hline$S(12)$ & 0.1551 & 0.3353 & 0.1980 & 0.0354 & 0.0314 & 0.0452 & 0.0857 & 0.0466 & 0.0672 & 0.3864 & 5 \\
\hline $\mathrm{S}(13)$ & 0.0732 & 0.3001 & 0.0934 & 0.0320 & 0.0397 & 0.0989 & 0.1192 & 0.0507 & 0.1927 & 0.7723 & 23 \\
\hline$S(14)$ & 0.0320 & 0.0933 & 0.1411 & 0.0361 & 0.0825 & 0.3544 & 0.0361 & 0.1925 & 0.0320 & 0.9032 & 27 \\
\hline$S(15)$ & 0.0174 & 0.0174 & 0.0320 & 0.1377 & 0.2706 & 0.2706 & 0.0458 & 0.1377 & 0.0706 & 0.8240 & 25 \\
\hline$S(16)$ & 0.1299 & 0.0537 & 0.1299 & 0.1299 & 0.0537 & 0.0239 & 0.4014 & 0.0537 & 0.0239 & 0.3760 & 4 \\
\hline$S(17)$ & 0.0576 & 0.0254 & 0.0298 & 0.0468 & 0.0565 & 0.1474 & 0.2899 & 0.1936 & 0.1530 & 0.9270 & 30 \\
\hline$S(18)$ & 0.0885 & 0.0414 & 0.0885 & 0.1277 & 0.0324 & 0.0513 & 0.0233 & 0.2006 & 0.3463 & 0.4130 & 6 \\
\hline$S(19)$ & 0.0606 & 0.0273 & 0.0899 & 0.0348 & 0.0329 & 0.0393 & 0.3652 & 0.1361 & 0.2138 & 0.5314 & 11 \\
\hline $\mathrm{S}(20)$ & 0.0371 & 0.0371 & 0.0371 & 0.0371 & 0.0865 & 0.0915 & 0.1768 & 0.3200 & 0.1768 & 0.7901 & 24 \\
\hline $\mathrm{S}(21)$ & 0.2232 & 0.3704 & 0.1189 & 0.1189 & 0.0272 & 0.0272 & 0.0272 & 0.0598 & 0.0272 & 0 & 1 \\
\hline $\mathrm{S}(22)$ & 0.0184 & 0.0184 & 0.0355 & 0.1264 & 0.0624 & 0.0355 & 0.1338 & 0.3653 & 0.2042 & 0.5414 & 12 \\
\hline $\mathrm{S}(23)$ & 0.0184 & 0.2587 & 0.0352 & 0.0309 & 0.2290 & 0.1953 & 0.1100 & 0.0687 & 0.0538 & 0.8833 & 26 \\
\hline$S(24)$ & 0.0834 & 0.0345 & 0.0401 & 0.0345 & 0.0345 & 0.0834 & 0.3653 & 0.1820 & 0.1426 & 0.6167 & 15 \\
\hline$S(25)$ & 0.1061 & 0.3463 & 0.2335 & 0.1421 & 0.0519 & 0.0304 & 0.0524 & 0.0203 & 0.0170 & 0.3423 & 3 \\
\hline$S(26)$ & 0.0282 & 0.0282 & 0.0282 & 0.0662 & 0.0459 & 0.1070 & 0.1606 & 0.3839 & 0.1517 & 0.6218 & 16 \\
\hline$S(27)$ & 0.0819 & 0.0372 & 0.0420 & 0.3789 & 0.0216 & 0.0216 & 0.0725 & 0.2305 & 0.1139 & 0.3359 & 2 \\
\hline$S(28)$ & 0.0241 & 0.0684 & 0.0241 & 0.0241 & 0.3413 & 0.1871 & 0.0916 & 0.1871 & 0.0521 & 0.6291 & 18 \\
\hline S(29) & 0.0292 & 0.0672 & 0.3761 & 0.2266 & 0.0769 & 0.1364 & 0.0292 & 0.0292 & 0.0292 & 0.5247 & 9 \\
\hline $\mathrm{S}(30)$ & 0.0640 & 0.0640 & 0.0474 & 0.1333 & 0.0329 & 0.0329 & 0.3781 & 0.2301 & 0.0173 & 0.5278 & 10 \\
\hline $\mathrm{S}(31)$ & 0.0386 & 0.0710 & 0.0802 & 0.0386 & 0.3353 & 0.0386 & 0.1766 & 0.1307 & 0.0906 & 0.6258 & 17 \\
\hline
\end{tabular}

${ }^{\mathrm{a}}$. $\mathrm{LB}=$ Larger-the-better.

\section{Discussion}

The results are discussed in this section, with pragmatic implications of design principles for learning tasks, sequences of learning tasks in fixed programs, and ways to create adaptive or personalized programs are addressed as well.

The sequence of criteria from the easiest to the most difficult is $S(21) \rightarrow S(27) \rightarrow S(25) \rightarrow S(16) \rightarrow S(12)$, and so on. In sequence of the nine criteria are: $C(1)$ Posture $\rightarrow C(5)$ Preparing effective visual aids $\rightarrow C(2)$ Eye contact $\rightarrow C(3)$ Gestures $\rightarrow C(6)$ Explaining visual aids $\rightarrow C(4)$ Voice variation $\rightarrow C(9)$ Closing the speech $\rightarrow C(7)$ Opening the speech $\rightarrow C(8)$ Organizing \& outlining the speech body. The results show that $C(8)$ Organizing the speech, $C(7)$ opening speech and $C(9)$ closing the speech elicit the most cognitive load in the participants, implying that 'the overall structure of what to be heard' matters more than anything else because public speaking also deals with the content they "plan" to talk. In particular, $C(8)(\mathrm{LGRG}=1)$ takes a much greater leap than $C(7)(\operatorname{LGRG}=0.6516)$, indicating $\mathrm{C}(8)$ alone causes heavy cognitive load when the participants learn to acquire this skill. Another great LGRG leap takes place 
Table 4. The 9 criteria' LGRG values and rankings.

\begin{tabular}{|c|c|c|c|c|c|c|c|c|c|c|c|}
\hline Criteria & $\mathrm{S}(1)$ & $S(2)$ & $\mathrm{S}(3)$ & $S(4)$ & $S(5)$ & $\mathrm{S}(6)$ & $S(7)$ & $\mathrm{S}(8)$ & $S(9)$ & $S(10)$ & $\mathrm{S}(11)$ \\
\hline $\mathrm{LB}^{\mathrm{a}}$ & 0.3162 & 0.2100 & 0.3696 & 0.2528 & 0.4005 & 0.3568 & 0.3531 & 0.2751 & 0.3283 & 0.4326 & 0.3162 \\
\hline$C(1)$ & 0.0948 & 0.0395 & 0.0352 & 0.0416 & 0.0273 & 0.0434 & 0.0312 & 0.0704 & 0.0447 & 0.0719 & 0.0743 \\
\hline$C(2)$ & 0.1292 & 0.0445 & 0.0399 & 0.1094 & 0.0273 & 0.0285 & 0.3531 & 0.0474 & 0.1192 & 0.0315 & 0.0381 \\
\hline$C(3)$ & 0.2087 & 0.0395 & 0.0485 & 0.0416 & 0.0273 & 0.0259 & 0.1304 & 0.1853 & 0.0635 & 0.0936 & 0.0298 \\
\hline$C(4)$ & 0.3162 & 0.0395 & 0.0813 & 0.2528 & 0.0273 & 0.2252 & 0.0337 & 0.2751 & 0.0593 & 0.0324 & 0.1356 \\
\hline$C(5)$ & 0.0550 & 0.0863 & 0.0674 & 0.0416 & 0.0704 & 0.0293 & 0.0207 & 0.0412 & 0.0411 & 0.0480 & 0.0354 \\
\hline$C(6)$ & 0.0743 & 0.1205 & 0.1068 & 0.0416 & 0.0704 & 0.0555 & 0.0388 & 0.0521 & 0.0368 & 0.4326 & 0.0487 \\
\hline$C(7)$ & 0.0290 & 0.2100 & 0.0790 & 0.2528 & 0.4005 & 0.1177 & 0.0741 & 0.1640 & 0.1222 & 0.0261 & 0.2477 \\
\hline $\mathrm{C}(8)$ & 0.0443 & 0.2100 & 0.03696 & 0.1094 & 0.1961 & 0.3568 & 0.2188 & 0.1015 & 0.03283 & 0.2307 & 0.3162 \\
\hline$C(9)$ & 0.0486 & 0.2100 & 0.1725 & 0.1094 & 0.1536 & 0.1177 & 0.0993 & 0.0628 & 0.1849 & 0.0333 & 0.0743 \\
\hline Criteria & $S(12)$ & $\mathrm{S}(13)$ & $S(14)$ & $S(15)$ & $S(16)$ & $S(17)$ & $\mathrm{S}(18)$ & $\mathrm{S}(19)$ & $S(20)$ & $S(21)$ & $S(22)$ \\
\hline $\mathrm{LB}^{\mathrm{a}}$ & 0.3353 & 0.3001 & 0.3544 & 0.2706 & 0.4014 & 0.2899 & 0.3463 & 0.3652 & 0.3200 & 0.3704 & 0.3653 \\
\hline$C(1)$ & 0.1551 & 0.0732 & 0.0320 & 0.0174 & 0.1299 & 0.0576 & 0.0885 & 0.0606 & 0.0371 & 0.2232 & 0.0184 \\
\hline$C(2)$ & 0.3353 & 0.3001 & 0.0933 & 0.0174 & 0.0537 & 0.0254 & 0.0414 & 0.0273 & 0.0371 & 0.3704 & 0.0184 \\
\hline$C(3)$ & 0.1980 & 1.0934 & 0.1411 & 0.0320 & 0.1299 & 0.0298 & 0.0885 & 0.0899 & 0.0371 & 0.1189 & 0.0355 \\
\hline$C(4)$ & 0.0354 & 0.0320 & 0.0361 & 0.1377 & 0.1299 & 0.0468 & 0.1277 & 0.0348 & 0.0371 & 0.1189 & 0.1264 \\
\hline$C(5)$ & 0.0314 & 0.0397 & 0.0825 & 0.2706 & 0.0537 & 0.0565 & 0.0324 & 0.0329 & 0.0865 & 0.0272 & 0.0624 \\
\hline$C(6)$ & 0.0452 & 0.0989 & 0.3544 & 0.2706 & 0.0239 & 0.1474 & 0.0513 & 0.0393 & 0.0915 & 0.0272 & 0.0355 \\
\hline$C(7)$ & 0.0857 & 0.1192 & 0.0361 & 0.0458 & 0.4014 & 0.2899 & 0.0233 & 0.3652 & 0.1768 & 0.0272 & 0.1338 \\
\hline $\mathrm{C}(8)$ & 0.0466 & 0.0507 & 0.1925 & 0.1377 & 0.0537 & 0.1936 & 0.2006 & 0.1361 & 0.3200 & 0.0598 & 0.3653 \\
\hline$C(9)$ & 0.0672 & 0.1927 & 0.0320 & 0.0706 & 0.0239 & 0.1530 & 0.3463 & 0.2138 & 0.1768 & 0.0272 & 0.2042 \\
\hline Students & $S(23)$ & $\mathrm{S}(24)$ & $\mathrm{S}(25)$ & $S(26)$ & $S(27)$ & $\mathrm{S}(28)$ & $\mathrm{S}(29)$ & $\mathrm{S}(30)$ & $\mathrm{S}(31)$ & $\begin{array}{l}\text { LGRG } \\
\text { (value) }\end{array}$ & Ranking \\
\hline $\mathrm{LB}^{\mathrm{a}}$ & 0.2587 & 0.3653 & 0.3463 & 0.3839 & 0.3789 & 0.3413 & 0.3761 & 0.3781 & 0.3353 & & \\
\hline $\mathrm{C}(1)$ & 0.0184 & 0.0834 & 0.1061 & 0.0282 & 0.0819 & 0.0241 & 0.0292 & 0.0640 & 0.0386 & 0 & 1 \\
\hline$C(2)$ & 0.2587 & 0.0345 & 0.3463 & 0.0282 & 0.0372 & 0.0684 & 0.0672 & 0.0640 & 0.0710 & 0.1734 & 3 \\
\hline$C(3)$ & 0.0352 & 0.0401 & 0.2335 & 0.0282 & 0.0420 & 0.0241 & 0.3761 & 0.0474 & 0.0802 & 0.2062 & 4 \\
\hline$C(4)$ & 0.0309 & 0.0345 & 0.1421 & 0.0662 & 0.3789 & 0.0241 & 0.2266 & 0.1333 & 0.0386 & 0.3173 & 6 \\
\hline$C(5)$ & 0.2290 & 0.0345 & 0.0519 & 0.0459 & 0.0216 & 0.3413 & 0.0769 & 0.0329 & 0.3353 & 0.0154 & 2 \\
\hline$C(6)$ & 0.1953 & 0.0834 & 0.0304 & 0.1070 & 0.0216 & 0.1871 & 0.1364 & 0.0329 & 0.0386 & 0.2225 & 5 \\
\hline$C(7)$ & 0.1100 & 0.3653 & 0.0524 & 0.1606 & 0.0725 & 0.0916 & 0.0292 & 0.3781 & 0.1766 & 0.6516 & 8 \\
\hline $\mathrm{C}(8)$ & 0.0687 & 0.1820 & 0.0203 & 0.3839 & 0.2305 & 0.1871 & 0.0292 & 0.2301 & 0.1307 & 1 & 9 \\
\hline$C(9)$ & 0.0538 & 0.1426 & 0.0170 & 0.1517 & 0.1139 & 0.0521 & 0.0292 & 0.0173 & 0.0906 & 0.3810 & 7 \\
\hline
\end{tabular}

${ }^{\text {a }}$ LB $=$ Larger-the-better.

from $\mathrm{C}(7)(\mathrm{LGRG}=0.6516)$ to $\mathrm{C}(9)(\mathrm{LGRG}=0.3810)$. These two great gaps make $C(7)$ and $C(8)$ stand out of the rest of skills. This finding reveals that speech instructors should take more time in designing the pedagogy when teaching students how to start a speech and how to present a speech logically. In addition, more practices are required in these two skills so as to decrease their cognitive load.

On the other hand, the responding students feel they have more grasps on $C(1)$ posture, $C(5)$ preparing effective visual aids, and $C(2)$ eye contact. $C(1)$ generates the least cognitive load among the tested criteria. Preparing effective visual aids ranks at the second place, implying that the creation of visual aids is a relatively an easy task to them, perhaps due to the fact that they are a generation immersed in the technology era. Eye contact, ranked 3rd, has a similar nature to posture - it is related to how to act on stage. In particular, $\mathrm{C}(1)$ and $\mathrm{C}(5)$, as the two easiest tasks, have very close LGRG values, i.e. 0 and close to 0 respectively, and their LGRG values lead the rest of criteria's LGRG values by a large margin. This finding indicates that, as $\mathrm{C}(1)$ and $\mathrm{C}(5)$ elicit the least amount of cognitive load, speech instructors should start teaching 
Table 5. The resulted grey-based student-construct (S-C) matrix.

\begin{tabular}{|c|c|c|c|c|c|c|c|c|c|c|}
\hline \multirow{2}{*}{ S-C } & $\mathrm{C}(1)$ & $C(5)$ & $C(2)$ & $C(3)$ & $C(6)$ & $C(4)$ & $\mathrm{C}(9)$ & $C(7)$ & $\mathrm{C}(8)$ & \multirow{2}{*}{$\begin{array}{l}\text { LGRG } \\
\text { (value) }\end{array}$} \\
\hline & 0 & 0.0154 & 0.1734 & 0.2062 & 0.2225 & 0.3173 & 0.3810 & 0.6516 & 1 & \\
\hline $\mathrm{S}(21)$ & 0.2232 & 0.0272 & 0.3704 & 0.1189 & 0.0272 & 0.1189 & 0.0272 & 0.0272 & 0.0598 & 0 \\
\hline$S(27)$ & 0.0819 & 0.0216 & 0.0372 & 0.0420 & 0.0216 & 0.3789 & 0.1139 & 0.0725 & 0.2305 & 0.3359 \\
\hline $\mathrm{S}(25)$ & 0.1061 & 0.0519 & 0.3463 & 0.2335 & 0.0304 & 0.1421 & 0.0170 & 0.0524 & 0.0203 & 0.3423 \\
\hline$S(16)$ & 0.1299 & 0.0537 & 0.0537 & 0.1299 & 0.0239 & 0.1299 & 0.0239 & 0.4014 & 0.0537 & 0.3760 \\
\hline $\mathrm{S}(12)$ & 0.1551 & 0.0314 & 0.3353 & 0.1980 & 0.0452 & 0.0354 & 0.0672 & 0.0857 & 0.0466 & 0.3864 \\
\hline $\mathrm{S}(18)$ & 0.0885 & 0.0324 & 0.0414 & 0.0885 & 0.0513 & 0.1277 & 0.3463 & 0.0233 & 0.2006 & 0.4130 \\
\hline $\mathrm{S}(10)$ & 0.0719 & 0.0480 & 0.0315 & 0.0936 & 0.4326 & 0.0324 & 0.0333 & 0.0261 & 0.2307 & 0.4410 \\
\hline $\mathrm{S}(5)$ & 0.0273 & 0.0704 & 0.0273 & 0.0273 & 0.0704 & 0.0273 & 0.1536 & 0.4005 & 0.1961 & 0.4998 \\
\hline$S(29)$ & 0.0292 & 0.0769 & 0.0672 & 0.3761 & 0.1364 & 0.2266 & 0.0292 & 0.0292 & 0.0292 & 0.5247 \\
\hline $\mathrm{S}(30)$ & 0.0640 & 0.0329 & 0.0640 & 0.0474 & 0.0329 & 0.1333 & 0.0173 & 0.3781 & 0.2301 & 0.5278 \\
\hline $\mathrm{S}(19)$ & 0.0606 & 0.0329 & 0.0273 & 0.0899 & 0.0393 & 0.0348 & 0.2138 & 0.3652 & 0.1361 & 0.5314 \\
\hline$S(22)$ & 0.0184 & 0.0624 & 0.0184 & 0.0355 & 0.0355 & 0.1264 & 0.2042 & 0.1338 & 0.3653 & 0.5414 \\
\hline $\mathrm{S}(7)$ & 0.0312 & 0.0207 & 0.3531 & 0.1304 & 0.0388 & 0.0337 & 0.0993 & 0.0741 & 0.2188 & 0.5666 \\
\hline$S(6)$ & 0.0434 & 0.0293 & 0.0285 & 0.0259 & 0.0555 & 0.2252 & 0.1177 & 0.1177 & 0.3568 & 0.5780 \\
\hline$S(24)$ & 0.0834 & 0.0345 & 0.0345 & 0.0401 & 0.0834 & 0.0345 & 0.1426 & 0.3653 & 0.1820 & 0.6167 \\
\hline$S(26)$ & 0.0282 & 0.0459 & 0.0282 & 0.0282 & 0.1070 & 0.0662 & 0.1517 & 0.1606 & 0.3839 & 0.6218 \\
\hline $\mathrm{S}(31)$ & 0.0386 & 0.3353 & 0.0710 & 0.0802 & 0.0386 & 0.0386 & 0.0906 & 0.1766 & 0.1307 & 0.6258 \\
\hline $\mathrm{S}(28)$ & 0.0241 & 0.3413 & 0.0684 & 0.0241 & 0.1871 & 0.0241 & 0.0521 & 0.0916 & 0.1871 & 0.6291 \\
\hline $\mathrm{S}(1)$ & 0.0948 & 0.0550 & 0.1292 & 0.2087 & 0.0743 & 0.3162 & 0.0486 & 0.0290 & 0.0443 & 0.6485 \\
\hline $\mathrm{S}(3)$ & 0.0352 & 0.0674 & 0.0399 & 0.0485 & 0.1068 & 0.0813 & 0.1725 & 0.0790 & 0.3696 & 0.6770 \\
\hline $\mathrm{S}(11)$ & 0.0743 & 0.0354 & 0.0381 & 0.0298 & 0.0487 & 0.1356 & 0.0743 & 0.2477 & 0.3162 & 0.6865 \\
\hline $\mathrm{S}(9)$ & 0.0447 & 0.0411 & 0.1192 & 0.0635 & 0.0368 & 0.0593 & 0.1849 & 0.1222 & 0.3283 & 0.7361 \\
\hline $\mathrm{S}(13)$ & 0.0732 & 0.0397 & 0.3001 & 0.0934 & 0.0989 & 0.0320 & 0.1927 & 0.1192 & 0.0507 & 0.7723 \\
\hline$S(20)$ & 0.0371 & 0.0865 & 0.0371 & 0.0371 & 0.0915 & 0.0371 & 0.1768 & 0.1768 & 0.3200 & 0.7901 \\
\hline$S(15)$ & 0.0174 & 0.2706 & 0.0174 & 0.0320 & 0.2706 & 0.1377 & 0.0706 & 0.0458 & 0.1377 & 0.8240 \\
\hline $\mathrm{S}(23)$ & 0.0184 & 0.2290 & 0.2587 & 0.0352 & 0.1953 & 0.0309 & 0.0538 & 0.1100 & 0.0687 & 0.8833 \\
\hline$S(14)$ & 0.0320 & 0.0825 & 0.0933 & 0.1411 & 0.3544 & 0.0361 & 0.0320 & 0.0361 & 0.1925 & 0.9032 \\
\hline $\mathrm{S}(8)$ & 0.0704 & 0.0412 & 0.0474 & 0.1853 & 0.0521 & 0.2751 & 0.0628 & 0.1640 & 0.1015 & 0.9190 \\
\hline $\mathrm{S}(4)$ & 0.0416 & 0.0416 & 0.1094 & 0.0416 & 0.0416 & 0.2528 & 0.1094 & 0.2528 & 0.1094 & 0.9260 \\
\hline$S(17)$ & 0.0576 & 0.0565 & 0.0254 & 0.0298 & 0.1474 & 0.0468 & 0.1530 & 0.2899 & 0.1936 & 0.9270 \\
\hline $\mathrm{S}(2)$ & 0.0395 & 0.0863 & 0.0445 & 0.0395 & 0.1205 & 0.0395 & 0.2100 & 0.2100 & 0.2100 & 1 \\
\hline
\end{tabular}

the two speech skills, from how to maintain a good posture and how to prepare visual aids, for students to quickly establish confidence in the beginning of the course.

The sequence of criteria from the easiest to the most difficult (Posture $\rightarrow$ Preparing effective visual aids $\rightarrow$ Eye contact $\rightarrow$ Gestures $\rightarrow$ Explaining visual aids $\rightarrow$ Voice variation $\rightarrow$ Closing the speech $\rightarrow$ Opening the speech $\rightarrow$ Organizing \& outlining the speech body) seems to indicate that motor skills are widely regarded as easy techniques to master by the participants, while the structure of the speech content poses more challenges to the participants. This finding coincides with Piaget's outline [28-30] of the course of human intellectual development from concrete experience or direct perception to abstraction or formal thinking. Hence, it can never be overemphasized that the teacher should constantly strengthen the practices on aspects such as posture, gesture, voice variation in the classroom to weaken the students' worries and anxieties in public speaking. In this way, students would feel better prepared when they tackle more challenging criteria (e.g., organization of the speech).

The amount of time required to profess a skill may be another plausible explanation of the sequence where motor skills tend to be regarded as easy techniques to 
master while the structure of the speech content is not. Unlike the motor skills, which can be acquired or fixed in a short period of time, to be professed in composing a well-structured speech is an ability which takes longterm planning and long time to cultivate. Hence, the responding students do not feel that their organizational ability in devising a speech content can be improved quickly in one single speech course alone. The participants' heavy cognitive load in the beginning, body and ending of a speech composition is more a reflection of their overall English ability than a reflection of their public speaking ability. Knowing how to compose a speech with a sound structure may actually be one kind of a priori knowledge, which gravely affects the status of cognitive load in students' public speaking. As the findings reflect $C(8)$ Organizing and outlining the speech body and $C(7)$ Opening the speech to be inadequate in the participants' a priori skills, remedial treatment should be provided to strengthen them.

More importantly, this result offers a new consideration of rearranging the sequence of taught materials in an English public speech class. Many speech textbooks currently available on the market starts from a general introductory section, then deals with the verbal and structural aspects of the speech, and then teaches delivering skills (including using visual aids), and finally ends with a section delineating different types of speech purposes. The result of this study challenges the prevalent sequence of contents in most textbooks.

From the most difficult to the easiest, Table 5 displays the cognitive load in sequence of the thirty-one students as $S(21) \rightarrow S(27) \rightarrow S(25) \rightarrow S(16) \rightarrow S(12), \ldots$, $\rightarrow S(2)$. The participant $S(2)$ located on the bottom of the consolidated matrix shared the consensus of what most participants have felt toward the difficulty levels of the nine criteria of skills; whereas the participant $\mathrm{S}(21)$ located on the top indicated the least consensus with other fellow students. In other words, $S(21)$ perceives the learning cognitive load significantly different from others. It is worth noting that $\mathrm{S}(21)$ has low LGRG values in all criteria except for two criteria-Eye contact and Posture, implying that $\mathrm{S}(21)$ feels comfortable about most of the English speech delivery skills but considers these two motor criteria significantly consuming her/his cognitive capacity. Accordingly, the teacher may offer individualized practices for $\mathrm{S}(21)$ by fostering eye contact and body posture skills. A focus on simply a couple of skills warrants enhancement of the participant's overall performance enormously.

\section{Conclusions}

This study systematically combines AHP and GRA to investigate the EFL students' perceptions in English public speaking training. Nine speech criteria representing the student competence in English public speech were extracted from a best-selling textbook Speaking of Speech (New/e) in Taiwan. Some 31 EFL-major university seniors in English Presentation Training class participated in the survey. The data analysis employed the Hierarchy Grey Relational Analysis (HGRA) to analyze the participants' perceived confidence in the criteria, sorted the data in order, and then located each participant's perceptions in a ranking matrix. The results from the easiest to the most difficult are sequenced in terms of the 31 participants $S(21) \rightarrow S(27) \rightarrow S(25) \rightarrow S(16) \rightarrow$ $S(12), \ldots, \rightarrow S(2)$ and in terms of the nine criteria Posture $\rightarrow$ Preparing effective visual aids $\rightarrow$ Eye contact $\rightarrow$ Gestures $\rightarrow$ Explaining visual aids $\rightarrow$ Voice variation $\rightarrow$ Closing the speech $\rightarrow$ Opening the speech $\rightarrow$ Organizing \& outlining the speech body.

Responding to students' feelings is important. By inviting students to express their cognitive load levels in learning targets, the teacher can help them overcome negative feelings that might otherwise obstruct their learning with a curriculum that corresponds to their cognitive load. When students' anxiety is reduced and self-confidence is boosted, skill acquisition is achieved more easily $[3,31]$. Competence and confidence will then be built in a positive cycle.

Based on the empirical results of this study, it can be summarized as follows. The teacher should start the training from posture and visual aids production for the students to have a sense of achievement, and refine the pedagogical skills with more emphases on the logical organization of the main points and attention getters in the beginning of the speech to strengthen a priori knowledge in these regards. To establish automatic skill schemas, the students should adjust their learning focuses with more practices on an attractive opening and a logical development of speech contents. Meanwhile, the teacher can even offer individualized programs to those whose cognitive load are largely different from the norm, i.e. $\mathrm{S}(21)$ and $\mathrm{S}(2)$.

Thus, this study has contributed to setting priority in designing a speech course by utilizing the research results from the cognitive load perspective. The application of a fine-tuned course design to suit the students' cognitive load and at the same time giving extra assistance in establishing skills schemas where the students lack confidence may be conducive to learning motivation and interest.

In terms of research limitations, first, the proposed data analysis procedure adopts Nagai's GRA formula, whereas other GRA equations can also be experimented in the future. Second, the proposed data analysis procedure is only attempted in a class of English Presentation Training in the case university. Third, the predefined nine criteria of skills were directly adopted from a bestselling textbook Speaking of Speech (New/e). Finally, the proposed procedure should be readily applicable to evalu- 
ate students' perception data in different aspects of public speaking for a more comprehensive understanding and training design of English public speaking. However, the most appropriate evaluation criteria affecting the cognitive load in different aspects must be reexamined.

\section{REFERENCES}

[1] Y. Zheng, "Anxiety and Second/Foreign Language Learning Revisited," Canadian Journal for New Scholars in Education, Vol. 1, No. 1, 2008, pp. 1-12.

[2] P. D. MacIntyre, "Language Anxiety: A Review of the Research for Language Teachers," In” D. J. Young, Ed., Affect in Foreign Language and Second Language Learning: A Practical Guide to Creating a Low-Anxiety Classroom Atmosphere, McGraw-Hill, Boston, 1999, pp. 2445 .

[3] D. Larsen-Freeman and M. Anderson, "Techniques and Principles in Language Teaching," Oxford University Press, Oxford, 2011.

[4] J. Sweller, "Cognitive Load Theory, Learning Difficulty, and Instructional Design," Learning and Instruction, Vol. 4, No. 4, 1997, pp. 295-312. doi:10.1016/0959-4752(94)90003-5

[5] C. C. Yang and B. S. Chen, "Supplier Selection Using Combined Analytical Hierarchy Process and Grey Relational Analysis," Journal of Manufacturing Technology Management, Vol. 17, No. 7, 2006, pp. 926-941. doi:10.1108/17410380610688241

[6] G. Zeng, R. Jiang, G. Huang, M. Xu and J. Li, "Optimization of Wastewater Treatment Alternative Selection by Hierarchy Grey Relational Analysis," Journal of Environmental Management, Vol. 82, No. 2, 2007, pp. 250-259. doi:10.1016/j.jenvman.2005.12.024

[7] A. Sarucan, M. E. Baysal, C. Kahraman and E. Orhan, "A Hierarchy Grey Relational Analysis for Selecting the Renewable Electricity Generation Technologies," Proceedings of the World Congress on Engineering (WCE) 2011, Vol. 2, London, 6-8 July 2011.

[8] T. L. Saaty, "Decision Making for Leaders: The Analytic Hierarchy Process for Decisions in a Complex World," RWS Publications, Pittsburgh, 2008.

[9] T. L. Saaty, "Relative Measurement and Its Generalization in Decision Making: Why pairwise comparisons Are Central in Mathematics for the Measurement of Intangible Factors: The Analytic Hierarchy/Network Process," Review of the Royal Spanish Academy of Sciences, Series A, Mathematics, Vol. 102, No. 2, 2008, pp. 251-318. doi:10.1007/BF03191825

[10] T. L. Saaty and K. Peniwati, "Group Decision Making: Drawing out and Reconciling Differences," RWS Publications, Pittsburgh, 2008.

[11] E. H. Forman and S. I. Gass, "The Analytical Hierarchy Process: An Exposition," Operations Research, Vol. 49, No. 4, 2001, pp. 469-487. doi:10.1287/opre.49.4.469.11231

[12] M. Bernasconi, C. Choirat and R. Seri, "The Analytic Hierarchy Process and the Theory of Measurement,"
Management Science, Vol. 56, No. 4, 2010, pp. 699-711. doi: $10.1287 / \mathrm{mnsc} .1090 .1123$

[13] J. L. Deng, "Control Problems of Grey Systems," Systems and Control Letters, Vol. 1, No. 6, 1982, pp. 288-294.

[14] K. L. Wen, C. H. Chao, H. C. Chang, H. Y. Chen and H. C. Wen, "Grey System Theory and Applications," Wunan Publisher, Taipei, 2009.

[15] J. C. Liang, J. R. Wang and L. H. Wang, "Kansei Product Design Based on the Personal's Hair Image," Journal of Grey System, Vol. 14, No. 1, 2011, pp. 29-40.

[16] J. C. Liang, Y. L. Lee and S. F. Liu, "Strategic Kansei Design for a Nice Doorplate Based on GRA," Journal of Grey System, Vol. 12, No. 4, 2009, pp. 177-184.

[17] Y. L. Lee, J. S. Chen, J. C. Liang, C. K. Wu and P. H. Kao, "Purchasing Decision and Design Strategy of High Heels in Female Consumer Market," International Journal of Kansei Information, Vol. 1, No. 1, 2010, pp. 1-8.

[18] I. M. Ar, C. Hamzacebi and B. Baki, "Business School Ranking with Grey Relational Analysis: The Case of Turkey," Grey Systems: Theory and Application, Vol. 3, No. 1, 2013, pp. 76-94.

[19] S. Pramanik and D. Mukhopadhyaya, "Grey Relational Analysis Based Intuitionistic Fuzzy Multi-Criteria Group Decision-Making Approach for Teacher Selection in Higher Education," International Journal of Computer Applications, Vol. 34, No. 1, 2011, pp. 21-29.

[20] Y. L. Lee, J. C. Liang, J. S. Chen and C. K. Wu, "The Best Materials Selection among Prototype Model Making Technique Based on QFD and GRA," IASTED Advances in Computer Science and Engineering 2010, Sharm El Sheikh, 15-17 March 2010, pp. 689-092.

[21] S. J. Huang, N. H. Chiu, and L. W. Chen, "Integration of the Grey Relational Analysis with Genetic Algorithm for Software Effort Estimation," European Journal of Operational Research, Vol. 188, No. 3, 2007, pp. 898-909. doi:10.1016/j.ejor.2007.07.002

[22] J. Sweller, "Cognitive Load during Problem Solving: Effects on Learning," Cognitive Science, Vol. 12, No. 2, 1988, pp. 257-285. doi:10.1207/s15516709 $\operatorname{cog} 1202 \_4$

[23] F. G. W. C. Paas and J. J. G. Van Merrienboer, "Variability of Worked Examples and Transfer of Geometrical Problem-Solving: A Cognitive-Load Approach," Journal of Educational Psychology, Vol. 86, No. 1, 1994, pp. 122133. doi:10.1037/0022-0663.86.1.122

[24] J. Sweller, "Cognitive Technology: Some Procedures for Facilitating Learning and Problem Solving in Mathematics and Science," Journal of Educational Psychology, Vol. 81, No. 4, 1989, pp. 457-466. doi:10.1037/0022-0663.81.4.457

[25] J. Sweller, J. J. G. Van Merrienboer and F. G. W. C. Paas, "Cognitive Architecture and Instructional Design," Educational Psychology Review, Vol. 10, No. 3, 1998, pp. 251296. doi:10.1023/A:1022193728205

[26] D. Harrington and C. LeBeau, "Speaking of Speech: Basic Presentation Skills for Beginners (New ed.)," Macmillan Language House Inc., Tokyo, 2009.

[27] K. L. Wen, "Grey Systems: Modeling and Prediction," 
Yang's Scientific Research Institute, Tucson, 2004.

[28] J. Piaget, "The Language and Thought of the Child," Meridian, New York, 1955.

[29] J. Piaget, "The Principles of Genetic Epistemology," Basics Books, New York, 1972.

[30] J. Piaget and B. Inhelder, "The Psychology of the Child," Basics Books, New York, 1969.
[31] D. J. Young, "Affect in Foreign Language and Second Language Learning: A Practical Guide to Creating a LowAnxiety Classroom Atmosphere," McGraw-Hills, Boston, 1999. 